\title{
Predicting Regional Recessions Via the Yield Spread
}

\section{Jean Gauger and Don Schunk*}

\begin{abstract}
This paper examines the ability of the slope of the yield curve to serve as a predictor of regional recessions. The ability of interest rate spreads to predict recessions has received considerable attention at the aggregate level. This paper offers evidence on the usefulness of rate spreads in predicting economic downturns at the regional level. The evidence points to regional differences in the ability of the U.S. yield curve to predict regional recessions. These differences are highlighted in the context of differing regional economic structures.
\end{abstract}

\section{INTRODUCTION}

Empirical research in recent years has identified the slope of the yield curve as a strong predictor for recessions in the aggregate economy. The interest rate "yield spread" measures the slope of the yield curve, and is given by the difference between a long-term and short-term government interest rate. In fact, several studies that evaluate the predictive power of a broad set of economic indicators find that the yield spread has better predictive power for longer-range recession predictions than do measures such as the widely known Index of Leading Economic Indicators and other complex indices. ${ }^{1}$ (See, for example, Estrella and Hardouvelis 1991 or Estrella and Mishkin 1998.)

Of the previous studies assessing the yield spread's aggregate-level predictive power, none clearly has identified a single explanation for why the yield spread predicts aggregate recessions well. Estrella, Rodrigues, and Schich (2000) summarize proposed explanations for the yield spread's identified predictive power for aggregate economic activity. In general, the yield spread's predictive power likely is tied in with its ability to synthesize efficiently the many factors that precede a recession, and to capture central bank efforts with interest rates. For example, current monetary policy significantly affects the yield curve spread and economic activity over the next several quarters. A monetary contraction has rapid impacts on short-term interest rates and tends to narrow the yield spread and slow future real economic activity. The yield spread also captures expectations about future real economic conditions, inflation, and real interest rates. Expectations become embodied in interest rates. Thus, for a variety of reasons, the

*Department of Economics, The University of Tennessee, Knoxville; and Department of Economics and Division of Research, Moore School of Business, The University of South Carolina, Columbia. This research was supported in part by a 2001 College of Business Scholarly Research Grant and the Department of Economics at The University of Tennessee.

1Estrella, Rodrigues and Schich (2000) provide a summary of studies (both U.S. and international) that identify strong relationships between the yield spread and aggregate-level economic activity. Since several previous studies evaluate the predictive performance of a variety of economic indicators, and consistently identify the yield spread as best performing, we do not repeat that assessment here. Our focus is on the regional performance question. 
steepness of the yield curve can be an excellent indicator of future aggregate-level economic activity.

Across the aggregate economy, changes in interest rates affect different regions with varying intensity. A recent wave of empirical research has shown that monetary policy actions or, more loosely, changes in monetary factors such as interest rates or the nominal money stock, have vastly differing impacts on economic activity across regions. Studies such as Carlino and DeFina $(1998,1999)$ and Schunk (1999) have relied on various forms of vector autoregressions (VARs) to estimate the dynamic relationship between, for example, changes in national interest rates and changes in regional real economic activity. ${ }^{2}$ These studies have produced consistent findings in the pattern of regional monetary impacts, in that regions that are relatively more dominated by interest-sensitive sectors tend to be the most responsive to monetary policy actions.

The yield spread, which in part embodies changes in the stance of monetary policy, should therefore be expected to have varying power in predicting regional recessions. The aggregate-level outcome is the sum of disaggregate regional impacts. Thus, the recession prediction power of the yield spread identified in previous aggregate-level studies will be an amalgam of the ability of the yield curve to predict recessions at the regional level.

The purpose of the current study is to evaluate the yield spread's predictive power for regional recessions, with a focus on uncovering explanations for differences across regions. Unlike the time series model approaches of Carlino and DeFina $(1998,1999)$ and Schunk $(1999)$, where the focus is on simulating the path of regional real economic growth following a monetary shock, this study utilizes the probit model approach (used by Estrella and Mishkin 1998 and others) to focus explicitly on predicting periods of regional recession. This study does not aim to explicitly model regional economic activity via a regional structural model. Rather, given the strong aggregate-level predictive power from the yield spread, this project investigates a next question of interest: the predictive power for regional recessions of the parsimonious yield spread model. Given prior evidence showing varying regional responsiveness to monetary variables, it is likely that the yield spread model will perform better in some regions than in others. The goal is to evaluate the model's performance across regions, and to identify those regions for which the parsimonious yield spread model offers valuable predictive power.

The next section briefly summarizes the probit model, the data, and the empirical analysis. Section 3 presents the empirical results and recession probability predictions, as well as interpretation of the results. Section 4 presents conclusions.

2In addition, there is work by geographers on the regional dimensions of money and financial activity. See, for example, Cohen (1998), Warf and Cox (1995), as well as others. 


\section{ECONOMETRIC MODEL AND EMPIRICAL ANALYSIS}

\section{The Model}

Given the strong performance of the yield spread model for the aggregate economy, the objective here is to evaluate the performance of the yield spread as a predictor for regional economic recessions. Following procedures in the benchmark Estrella and Mishkin (1998) study, a probit model is used to predict periods of recession. Full discussion of the probit model can be found in Goldberger (1964), Maddala (1983), and several studies by Estrella and others (see, for example, Estrella and Hardouvelis 1991; Estrella and Mishkin 1996, 1998; Estrella 1998; and Estrella, Rodrigues, and Schich 2000). Briefly, a probit model is a limited dependent variable model in which the dependent variable takes one of two values: a value of one if a designated event occurs, zero otherwise. Limited dependent variable models have been used widely to assess a variety of discrete choice issues, often in microeconomic applications such as the probability of voting for a particular issue. In macroeconomic projects, it is more common to see models using a continuous dependent variable (such as economic growth). However, over the last ten years, limited dependent variable techniques have been used to predict recessions in macroeconomic activity. Recently, Estrella, Rodrigues, and Schich (2000) evaluated forecasting models using a continuous dependent variable (i.e., economic growth) versus binary models (i.e., dependent variable identifies recession eras). They found that binary models performed better and were more stable than continuous models. Thus, this project proceeds with the probit model methods successfully used in the aggregate-level studies.

In this project, the focus is on the performance of the model for regional activity, and the limited dependent variable captures whether a recession does or does not occur in a regional economy. Following Estrella and Mishkin (1998), a set of probit models is estimated for each region using forecast horizons (denoted " $k$ ") that vary from one to eight quarters in the future. Therefore, for each region, models of the following form are estimated:

$$
\operatorname{Prob}\left(R_{t+k}=1\right)=F\left(\alpha+\beta \text { Spread }_{t}\right),
$$

where $k=1,2, \ldots, 8$ is the forecasting horizon, $R_{t+k}$ is a binary variable denoting recession in the region ( $R_{t+k}=1$ if recession; 0 otherwise), $\beta$ is the coefficient on the interest rate yield spread variable, and $\alpha$ is a constant. ${ }^{3}$

Several performance criteria can be used to assess the predictive power of the yield spread. The $t$-statistic and associated probability value for statistical significance are standard criteria for evaluating a variable's explanatory power in a probit model. Another useful criterion is a goodness-of-fit measure, such as the

${ }^{3}$ The goal is to explore the usefulness of the yield spread in making recession predictions for a specific region. That is, the interest is in the reduced-form relationship between the yield spread and regional activity as opposed to estimating an underlying structural model explaining how the yield spread affects regional activity. If the goal were to determine the precise channel through which changes in the yield spread impact regional economies, then it would be necessary to explicitly account for the presence of interregional relationships. For the current purpose, however, this is not necessary. The separate single-equation probit models are sufficient to examine the pure predictive power of the yield spread. 
well-known $R^{2}$ measure in a linear regression model. The goodness-of-fit measure used here is a pseudo $R^{2}$ developed by Estrella (1998) and used in the Estrella and Mishkin (1998) aggregate-level study. (See Estrella 1998 for further discussion.) Its interpretation is analogous to the standard $R^{2}$ reported in linear regression models. Note that, for limited dependent variable models such as a probit model, a small $R^{2}$ (or pseudo $R^{2}$ ) is common. Correlations between binary dependent variables and the predicted probabilities are often low, leading to low $\mathrm{R}^{2}$ values. ${ }^{4}$

Another performance criterion to assess the yield spread's predictive power is the estimated probability of a recession. This is derived using the data on the yield spread variable and the parameter estimates from Equation 1. The probabilities are estimated from the "fitted values" of the dependent variable, and lie continuously within the $(0,1)$ interval. According to this criterion, the stronger the association between an increase in estimated probabilities and the actual contractions in the different regions, the stronger is the predictive power of the yield curve slope. The next section addresses the data used in the estimation.

\section{Data and Empirical Analysis}

To proceed with the probit modeling methods, time series data are needed for regional economic activity and the interest rates in the yield spread measure. The Bureau of Economic Analysis (BEA) reports measures of regional economic activity for eight regions of the contiguous United States. A variety of regional economic indicators initially was evaluated, and the performance was consistent across indicators. Data on earnings or personal income for these BEA regions have been used in a variety of studies of regional economic activity (see, for example, Garrison and Chang 1979; Carlino and DeFina 1998, 1999; and Schunk 1999). Use of this data allows comparability of findings across studies. Real earnings for each of the eight regions are used to identify periods of recession for each region. ${ }^{5}$ As a benchmark for the regional results, aggregate economic activity is also assessed using the National Bureau of Economic Research (NBER) dates of aggregate-level recessions. Quarterly data from 1969:2 to 1998:2 are used in model estimation; forecasts extend to $1999: 4 .^{6}$

4The predicted value in a probit model is a probability, while the actual value of the dependent variable is either 0 or 1 . Maddala (1983) notes that low $R^{2}$ values are common when calculating correlations between a binary dependent variable and the predicted probabilities. Thus, a low $R^{2}$ does not imply poor predictive power of the model.

${ }^{5}$ Nominal earnings data for the eight BEA regions are deflated by the Consumer Price Index. Considering the earnings series versus the total personal income series, the earnings series captures labor income generated within the state or region, thus capturing economic activity in the state or region. The personal income series also includes rent income, dividends, interest, and transfer payments, and thus includes components that may not attach to current economic activity in the state. For example, transfer payments may stabilize income and are not generated by real economic activity. The goal here is to capture the swings in economic activity, which are captured in the earnings data and may be masked by the total income data. Results are robust across use of the real earnings or real income data, although patterns are muted for the income data, as one would predict.

${ }^{6}$ The BEA makes available a consistent package of regional data, beginning in 1969. Data such as personal income can be obtained back to 1940, however this data is less user-friendly than the cohesive data package with the 1969 starting date. In addition, over the 1940s and 1950s, several factors affected interest rate determination. During World War II, the Federal Reserve pegged interest rates at low levels (to help the Treasury finance the war more cheaply), although this effectively relinquished control of monetary policy. The Federal Reserve reclaimed control of monetary policy in 1951, with the Federal Reserve-Treasury Accord. The 1969 starting date here avoids these periods of pegging and the post-Accord adjustment. 
To identify periods of recession within each region, quarterly growth rates in real earnings are calculated for each of the eight BEA regions. Based on an inspection of growth rates, a binary variable is created to identify periods of regional recession using the standard definition of recession: two consecutive quarters (or more) of negative growth. ${ }^{7}$

The yield spread typically is measured by the difference between a longterm government interest rate and a short-term government interest rate. In this study, the yield spread is measured by the difference between the 10-year Treasury bond rate and the 3-month Treasury bill rate, which matches the specification used in the Estrella and Mishkin (1998) study. Yield spread movements are similar across use of alternative rates (such as the 30-year Treasury rate for the longterm rate or 6-month Treasury rate for the short-term rate). Interest rate data, reported by the Federal Reserve System, are obtained from the St. Louis Federal Reserve Economic Data (FRED) web site (http://www.stls.frb.org/fred/). Figure 1 shows the yield spread over the sample period. As is evident, the yield spread generally has a positive value, corresponding to the positive slope for the typical yield curve on government interest rates. A narrower yield spread, which may be caused by a contractionary monetary action, altered economic expectations, or more benign inflation forecasts, indicates a flatter slope to the yield curve. As the several aggregate-level studies have shown, this can be a useful signal of upcoming weakness in the aggregate economy.

FIGURE 1

Yield Spread: 10-Year Bond - 3-Month Bill 1969:2 - 1999:4

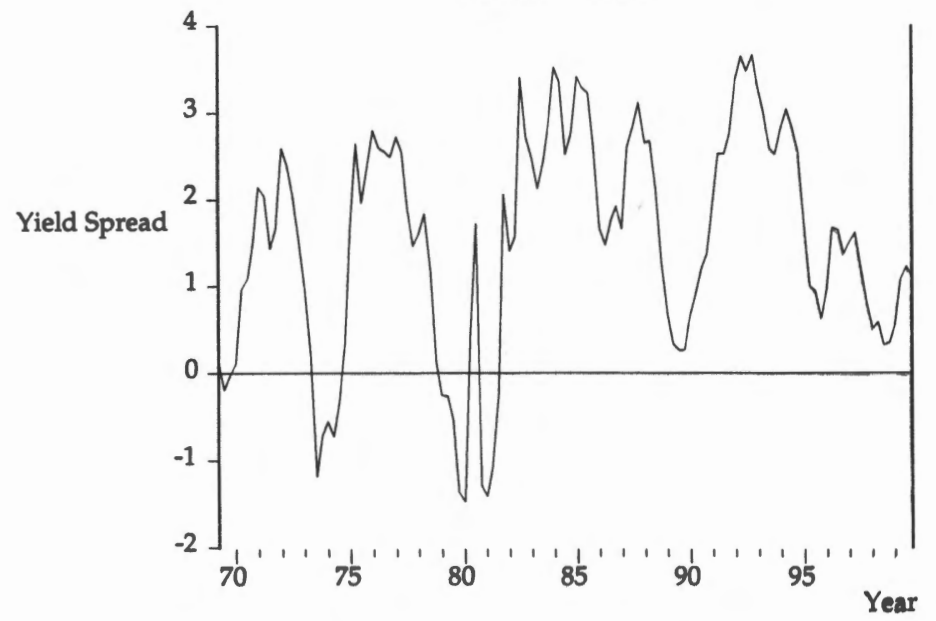

7Here, the guideline for coding as a "recession" was two or more consecutive quarters of negative growth in the region. Examination of aggregate GDP growth rates versus official NBER recession dates makes evident that official recession dates sometimes include quarters of weakness surrounding quarters of negative growth. Similar episodes in the regional data were evaluated. Coding followed the "two consecutive negative quarters" guideline, with a few minor exceptions. In the Southwest, continued weakness in late 1974 is included in the 1974 recession (SW2=1 in 1974:3,4). In the Southeast, Plains, and Far West, fluctuating growth surrounding longer contractions is included in recessions as follows: SE2=1 for 1981:2,3 and 1982:2,3; FW2=1 for 1974:1,2,3; Plains2=1 for 1970:2,3,4 and 1999:1,2,3 and Plains2=0 for 1976:2,3. Patterns in the BEA's alternative regional measures (for example, real total income) support these recession codings. 
Using the data on regional recessions and the yield spread measure, probit models are estimated for each region across several forecast horizons. The parameter estimates from the probit model can be used to calculate the predicted probability of recession in each region. Discussion turns next to these regional results.

\section{REGIONAL RESULTS}

As discussed, the yield spread data (period $t$ ) can be used to predict future recessions (in period $t+k$ ). The explanatory power of the yield spread will vary according to the forecast horizon used (number of quarters ahead on the prediction) and the character of the regional economy assessed. Table 1 reports results for each of the eight BEA regions, and for the aggregate economy, across various forecast horizons. Using forecast horizons from one to eight quarters, Table 1 reports the $t$-test statistics for the yield spread parameter, the associated probability level of significance (denoted p-value), and the pseudo $\mathrm{R}^{2}$ used in Estrella and Mishkin (1998). A probability level of $5 \%$ or smaller indicates that the yield spread contributes significantly to predicting regional recessions at that forecast horizon. The negative t-statistics, reflecting the underlying negative yield spread coefficients, are consistent with expectations. A monetary contraction influences shortterm rates more rapidly than it does long-term rates, thus narrowing the interest rate yield spread. This often is associated with slowed real economic activity in the future, although the strength and timing of the impacts vary, depending on the dominant character of the regional economy.

The major interests in the Table 1 results are to evaluate whether the yield spread contributes significantly to predicting regional recessions, and to identify the optimal forecast horizon for each region. The optimal forecast horizon is identified as that with the largest pseudo $\mathrm{R}^{2}$. For readers' convenience, an asterisk notes each region's optimal forecasting horizon (referred to as the "optimal $\mathrm{k}^{\prime}$ ).

As is evident from Table 1, the yield spread has significant predictive power for all regions. The yield spread parameter is significant across multiple forecast horizons for all regions, although the optimal forecast horizon generally is three quarters or less. The pseudo $R^{2}$ gives a measure of overall explanatory power of the yield spread model for each region. Looking at the pseudo $R^{2}$ at each region's optimal forecast horizon, it is apparent that the yield spread model performs well in a number of U.S. regions. For several major regions, the predictive power is even stronger than that for the overall economy. For example, the pseudo $R^{2}$ for the overall economy is about $40 \%$ (at the optimal $k$ ). The predictive power for the Great Lakes region is much stronger (ps. $R^{2}=50 \%$ ). This is consistent with results elsewhere indicating relatively stronger responses to economic shocks in the Great Lakes region. (See, for example, Garrison and Chang 1979, Carlino and DeFina 1998, Schunk 1999, and others.) 
TABLE 1

Regional Results-Earnings

Measures of Fit for Probit Model, 1969:2-1998:2

$\mathrm{p}\left(\mathrm{R}_{\mathrm{t+k}}=1\right)=\mathrm{F}\left(\alpha_{0}+\alpha_{1}\right.$ Spread $), \mathrm{k}=\mathrm{qtrs}$ ahead in forecast

\begin{tabular}{|c|c|c|c|c|c|c|c|c|}
\hline Spread $_{t-k}$ & 1 & 2 & 3 & 4 & 5 & 6 & 7 & 8 \\
\hline \multicolumn{9}{|c|}{ New England Region } \\
\hline $\begin{array}{l}\text { t-stat } \\
\text { p-value } \\
\text { Ps. } R^{2} c\end{array}$ & $\begin{array}{c}-5.685 \\
.000 \\
.4745^{*}\end{array}$ & $\begin{array}{c}-5.718 \\
.000 \\
.4377\end{array}$ & $\begin{array}{c}-5.371 \\
.000 \\
.3178\end{array}$ & $\begin{array}{c}-4.624 \\
.000 \\
.2106\end{array}$ & $\begin{array}{c}-3.687 \\
.000 \\
.1250\end{array}$ & $\begin{array}{c}-2.909 \\
.004 \\
.0751\end{array}$ & $\begin{array}{c}-2.030 \\
.042 \\
.0360\end{array}$ & $\begin{array}{l}-.8160 \\
.415 \\
.0058\end{array}$ \\
\hline \multicolumn{9}{|c|}{ Mideast Region } \\
\hline $\begin{array}{l}\text { t-stat } \\
\text { p-value } \\
\text { Ps. R2 }\end{array}$ & $\begin{array}{c}-5.518 \\
.000 \\
.3794\end{array}$ & $\begin{array}{c}-5.525 \\
.000 \\
.4000^{*}\end{array}$ & $\begin{array}{c}-5.383 \\
.000 \\
.3491\end{array}$ & $\begin{array}{c}-5.035 \\
.000 \\
.2694\end{array}$ & $\begin{array}{c}-4.413 \\
.000 \\
.1886\end{array}$ & $\begin{array}{c}-4.155 \\
.000 \\
.1637\end{array}$ & $\begin{array}{c}-3.493 \\
.000 \\
.1120\end{array}$ & $\begin{array}{c}-2.122 \\
.034 \\
.0395\end{array}$ \\
\hline \multicolumn{9}{|c|}{ Great Lakes Region } \\
\hline $\begin{array}{l}\text { t-stat } \\
\text { p-value } \\
\text { Ps. R }\end{array}$ & $\begin{array}{c}-5.564 \\
.000 \\
.3397\end{array}$ & $\begin{array}{c}-5.902 \\
.000 \\
.4589\end{array}$ & $\begin{array}{l}-5.675 \\
.000 \\
.4965^{*}\end{array}$ & $\begin{array}{c}-5.615 \\
.000 \\
.3973\end{array}$ & $\begin{array}{c}-5.295 \\
.000 \\
.3161\end{array}$ & $\begin{array}{c}-4.985 \\
.000 \\
.2621\end{array}$ & $\begin{array}{c}-4.163 \\
.000 \\
.1686\end{array}$ & $\begin{array}{r}-2.917 \\
.004 \\
.0775\end{array}$ \\
\hline \multicolumn{9}{|c|}{ Plains Region (P2) } \\
\hline $\begin{array}{l}\text { t-stat } \\
\text { p-value } \\
\text { Ps. } R^{2}\end{array}$ & $\begin{array}{c}-4.770 \\
.000 \\
.2307\end{array}$ & $\begin{array}{c}-4.996 \\
.000 \\
.2538^{*}\end{array}$ & $\begin{array}{c}-4.549 \\
.000 \\
.1972 \\
\end{array}$ & $\begin{array}{c}-4.043 \\
.000 \\
.1496\end{array}$ & $\begin{array}{r}-3.742 \\
.000 \\
.1277\end{array}$ & $\begin{array}{c}-2.783 \\
.005 \\
.0685\end{array}$ & $\begin{array}{c}-1.685 \\
.092 \\
.0246\end{array}$ & $\begin{array}{l}-.6349 \\
.526 \\
.0035\end{array}$ \\
\hline \multicolumn{9}{|c|}{ Southeast Region (SE2) } \\
\hline $\begin{array}{l}\text { t-stat } \\
\text { p-value } \\
\text { Ps. } R^{2}\end{array}$ & $\begin{array}{c}-5.422 \\
.000 \\
.3831\end{array}$ & $\begin{array}{c}-5.529 \\
.000 \\
.4471^{*}\end{array}$ & $\begin{array}{c}-5.200 \\
.000 \\
.3192\end{array}$ & $\begin{array}{c}-4.700 \\
.000 \\
.2347\end{array}$ & $\begin{array}{c}-4.256 \\
.000 \\
.1835\end{array}$ & $\begin{array}{c}-3.478 \\
.001 \\
.1141\end{array}$ & $\begin{array}{c}-2.287 \\
.022 \\
.0464\end{array}$ & $\begin{array}{r}-1.232 \\
.218 \\
.0132\end{array}$ \\
\hline \multicolumn{9}{|c|}{ Southwest Region (SW2) } \\
\hline $\begin{array}{l}\text { t-stat } \\
\text { p-value } \\
\text { Ps. } \text { R }^{2}\end{array}$ & $\begin{array}{c}-2.959 \\
.003 \\
.0849^{*}\end{array}$ & $\begin{array}{c}-2.518 \\
.012 \\
.0581\end{array}$ & $\begin{array}{c}-2.061 \\
.039 \\
.0374\end{array}$ & $\begin{array}{c}-1.942 \\
.052 \\
.0330\end{array}$ & $\begin{array}{r}-1.594 \\
.111 \\
.0220\end{array}$ & $\begin{array}{l}-.8090 \\
.419 \\
.0056\end{array}$ & $\begin{array}{l}.8188 \\
.413 \\
.0059\end{array}$ & $\begin{array}{c}1.732 \\
.083 \\
.0302 \\
\end{array}$ \\
\hline \multicolumn{9}{|c|}{ Rocky Mountain Region } \\
\hline $\begin{array}{l}\text { t-stat } \\
\text { p-value } \\
\text { Ps. R2 }\end{array}$ & $\begin{array}{c}-4.166 \\
.000 \\
.2310^{*} \\
\end{array}$ & $\begin{array}{r}-3.749 \\
.000 \\
.1530 \\
\end{array}$ & $\begin{array}{c}-2.857 \\
.004 \\
.0763 \\
\end{array}$ & $\begin{array}{c}-2.724 \\
.006 \\
.0682 \\
\end{array}$ & $\begin{array}{r}-2.380 \\
.017 \\
.0509 \\
\end{array}$ & $\begin{array}{c}-1.452 \\
.146 \\
.0182 \\
\end{array}$ & $\begin{array}{l}-.2257 \\
.821 \\
.0004\end{array}$ & $\begin{array}{l}.4829 \\
.629 \\
.0021 \\
\end{array}$ \\
\hline \multicolumn{9}{|c|}{ Far West Region (EW2) } \\
\hline $\begin{array}{l}\text { t-stat } \\
\text { p-value } \\
\text { Ps. } \text { R }^{2}\end{array}$ & $\begin{array}{c}-5.436 \\
.000 \\
.4070\end{array}$ & $\begin{array}{c}-5.614 \\
.000 \\
.4502^{*} \\
\end{array}$ & $\begin{array}{c}-5.733 \\
.000 \\
.4417\end{array}$ & $\begin{array}{c}-5.509 \\
.000 \\
.4290\end{array}$ & $\begin{array}{c}-5.143 \\
.000 \\
.3421\end{array}$ & $\begin{array}{c}-4.417 \\
.000 \\
.2086\end{array}$ & $\begin{array}{c}-3.162 \\
.002 \\
.0934\end{array}$ & $\begin{array}{c}-2.025 \\
.043 \\
.0364\end{array}$ \\
\hline \multicolumn{9}{|c|}{ Aggregate Economy } \\
\hline $\begin{array}{l}\text { t-stat } \\
\text { p-value } \\
\text { Ps. } R^{2}\end{array}$ & $\begin{array}{c}-4.499 \\
.000 \\
.2076\end{array}$ & $\begin{array}{c}-5.190 \\
.000 \\
.3373 \\
\end{array}$ & $\begin{array}{c}-5.394 \\
.000 \\
.3950^{*}\end{array}$ & $\begin{array}{c}-5.103 \\
.000 \\
.3200 \\
\end{array}$ & $\begin{array}{c}-4.843 \\
.000 \\
.2775\end{array}$ & $\begin{array}{c}-4.140 \\
.000 \\
.1807\end{array}$ & $\begin{array}{c}-2.965 \\
.003 \\
.0826 \\
\end{array}$ & $\begin{array}{r}-2.172 \\
.030 \\
.0425 \\
\end{array}$ \\
\hline
\end{tabular}

a $t$-stat denotes the $t$-statistics for the spread coefficient in the probit model.

${ }^{b} p$-value denotes the significance level for the t-test on the spread coefficient.

c Ps. $R^{2}$ denotes the pseudo $R$ squared.

In general, regions can be grouped according to whether the predictive power of the model dominates, matches, or is weaker than that for the overall economy (based on the pseudo $\mathrm{R}^{2}$ at the optimal $\mathrm{k}$ ). The regions where the model shows the strongest performance are the Great Lakes and New England. Strong performance - comparable to the aggregate economy-is also found for the Southeast, Mideast, and Far West. Performance weaker than that for the aggregate economy is found for the Rocky Mountain, Plains, and Southwest regions. Performance in the Southwest is notably weaker than all other regions. This pattern of results for regional monetary impacts is consistent with findings in several 
other regional studies (using different methods). However, some interesting differences do arise. For example, Garrison and Chang (1979) assess differential regional impacts of monetary policy prior to 1980 and find particularly strong impacts in the Great Lakes region and small impacts in the Rocky Mountain region..$^{8}$ Carlino and DeFina (1998) use impulse response functions from structural VARs to assess regional impacts of monetary policy actions (measured by the federal funds rate) over the period 1958 to 1992. They identify core regions (New England, Mideast, Southeast, Far West, and Plains) that respond to monetary shocks similarly to the average U.S. and non-core regions. The Great Lakes region is identified as very sensitive to monetary policy changes; the Southwest and Rocky Mountain regions are less sensitive to monetary policy. In further assessment, Carlino and DeFina (1998) conclude that there is support for the interest rate as a transmission mechanism, but not for a credit channel. Schunk (1999) also uses structural VARs to assess regional responsiveness to monetary shocks, looking at both federal funds rate shocks and monetary aggregate shocks. Focusing on results for interest rate shocks, Schunk (1999) finds strong responses in the Great Lakes, New England, Southeast, and Far West. Regions with weak interest rate impacts are the Southwest, Rocky Mountain, Mideast, and Plains regions. ${ }^{9}$

Thus, results from previous studies are consistent with evidence in Table 1. Where regions are responsive to monetary policy (such as the Great Lakes, New England, Southeast, and Far West), we would anticipate good predictive power for regional economic activity from the yield spread model. For regions less responsive to monetary policy, we would not expect good predictive power from the yield spread. Results here fit this pattern, with the exception of the Plains and Mideast (where responsiveness evidence is mixed).

The model has weak predictive power for regions such as the Southwest or Rocky Mountains. As noted, Schunk (1999) finds weak responses to a federal funds rate shock in the Southwest and Rocky Mountain regions, and it follows that the yield spread model, based upon interest rate movements, might have weak explanatory power in this region. In some cases, the model does a poor job predicting recessions because those regions do not have frequent and prolonged recessions. When the overall economy falls into recession, these regions more commonly have slowdowns rather than overt recessions. The probit model does not predict well in these cases. For example, between 1969 and 1999, the aggregate economy was in recession for 21 quarters. The Rocky Mountain and Southwest

\footnotetext{
${ }^{8}$ In his assessment of regional responses to monetary policy changes over 1952-1975, Toal (1977) finds stronger responses in the Mideast, Great Lakes, and Southeast regions; weaker responses are found for the Rocky Mountain and New England regions. With the exception of New England, results here are consistent with Toal's (1977) pre-1980 findings.

9More specifically, Schunk (1999) finds strong interest rate and monetary aggregate impacts for the Great Lakes, Southeast, and Far West. For New England, he finds strong interest rate, but weak monetary aggregate, impacts. Weak impacts from either measure of monetary policy are found for the Southwest, Rocky Mountain, and Mideast. The Plains region is found to have strong impacts from monetary aggregate shocks, but weak interest rate impacts. Schunk (1999) concludes that, for many regions, the interest rate is an important transmission mechanism. However, for some regions, such as the Plains, the credit channel may be more important. Schunk (1999) provides further interpretation for this pattern of findings.
} 
regions had only 12 quarters in recession over the same period..$^{10}$ Thus, the model's weak predictive power for some regions, such as the Southwest and Rocky Mountains, arises not only from weak regional responses to monetary actions, but the less frequent incidence of overt recessions in some regions.

The goodness-of-fit measures in Table 1 are one means to evaluate performance of the model. ${ }^{11}$ Another key interest is how the model's predicted recession probabilities for each region compare to actual recession episodes. The discussion turns next to the predicted probabilities of regional recessions from the probit model.

\section{Regional Predictions of Recession}

Using the probit model results, the probability of recession can be calculated at each forecast horizon. Using each region's optimal forecast horizon (as indicated in Table 1), Figures 2 through 10 show the predicted probability of recession for each region and for the overall economy. Note that the vertical scale may differ across graphs. Thus, what looks like a big spike in predicted probability for the Rocky Mountain region may be to a maximum probability of $40 \%$, while for the Great Lakes, it may be to a maximum probability of $90 \%$. For each graph, the shaded bars indicate periods of recession in that region (unless otherwise noted). Recall from earlier discussion that some regions tend to have few overt recessions. In a few relevant cases discussed, a one-period contraction (and surrounding weak growth) is noted for the reader on the figures. In interpreting regional results, it is useful to keep in mind events in the aggregate economy.

As a benchmark for regional results, the predicted probability results for the aggregate economy are presented first. Figure 2 reveals strong signals from the yield spread prior to aggregate-level recessions. For example, the model was indicating a probability of recession of $90 \%$ prior to the recessions in the early 1980 s. This is a notable signal, given the typically low probabilities of recession in nonrecessionary periods. ${ }^{12}$ The simple yield spread model has good predictive power for the aggregate economy. The aggregate results here correspond well to those in

\footnotetext{
${ }^{10}$ The model's best predictive performance corresponds to those regions in which contractions have prolonged impacts. Evaluating regional recessions' timing and duration shows that the Great Lakes and New England are hit by recession earlier and episodes last longer compared to the aggregate economy. (The Great Lakes had 30 quarters of recession across five episodes; New England had 27 quarters of recession across four episodes.)

${ }^{11}$ The out-of-sample forecasting performance of these probit models was also examined using an approach similar to that of Estrella and Mishkin (1998). In their paper, Estrella and Mishkin (1998) find that the out-of-sample predictive power of the yield spread at the U.S. level is actually greater than the in-sample power. We reach the same conclusion looking at our U.S. results. Our out-of-sample analysis shows that the aggregate-level power of the yield spread rises from $39.5 \%$ to $43.1 \%$. Our regional analysis allows us to pinpoint the source of this out-ofsample improvement. For every region except the Far West, the out-of-sample predictive power of the yield spread fell relative to the in-sample results. However, for the Far West region, the pseudo $\mathrm{R}^{2}$ rose from $45 \%$ in-sample to $54.5 \%$ out-of-sample. While the out-of-sample predictive power for the remaining regions declined marginally, the overall patterns were unchanged. The Far West, New England, and Great Lakes regions continue to see the highest pseudo $R^{2}$ s, while the Plains, Rocky Mountain, and Southwest regions posted the lowest pseudo $R^{2}$ s.

${ }^{12}$ As Estrella and Mishkin (1996, p. 4) point out in their aggregate study, "In assessing these panels, note that even a probability of recession that is considerably less than one can be a strong signal of recession. Because in any given quarter the probability of recession is quite low, a forecasted probability of, say, 50 percent is going to be quite unusual. Indeed, the successful forecasting model...yields probabilities of recession that are typically below 10 percent in nonrecession (unshaded) periods.... Thus, even a probability of recession of 25 percent...[is] a relatively strong signal...that a recession might come in the future."
} 
the Estrella and Mishkin (1998) study. Since aggregate results here serve primarily as a benchmark, they will not be discussed in full detail (See Estrella and Mishkin 1998 for full coverage of their aggregate results). Further discussion of aggregate results focuses on patterns as they relate to the regional results or recent time periods not evaluated in the Estrella and Mishkin (1998) study.

FIGURE 2

Probability of Recession: Aggregate Economy

3 Qtr. Ahead Forecast

1969:2 - 1999:4

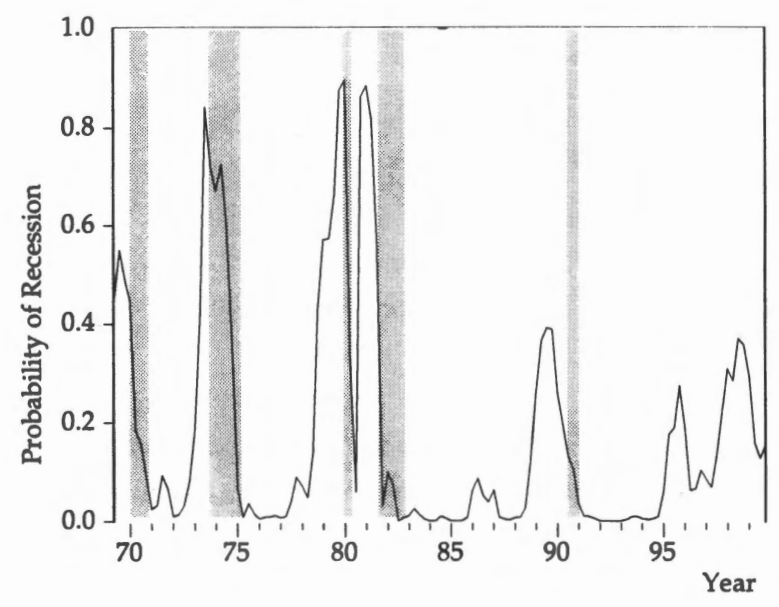

FIGURE 3

Probability of Recession: Great Lakes Region

3 Qtr. Ahead Forecast

1969:2 - 1999:4

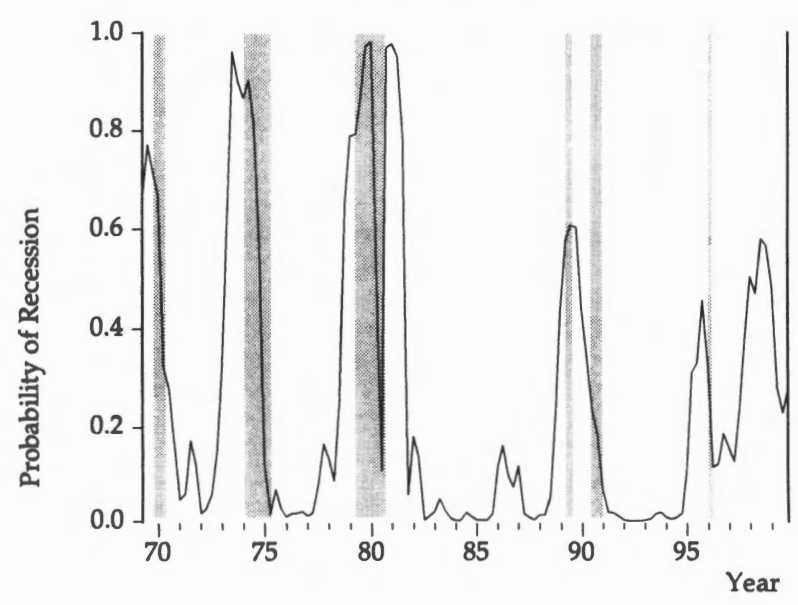


FIGURE 4

Probability of Recession: New England Region

1 Qtr. Ahead Forecast, 1969:2 - 1999:4

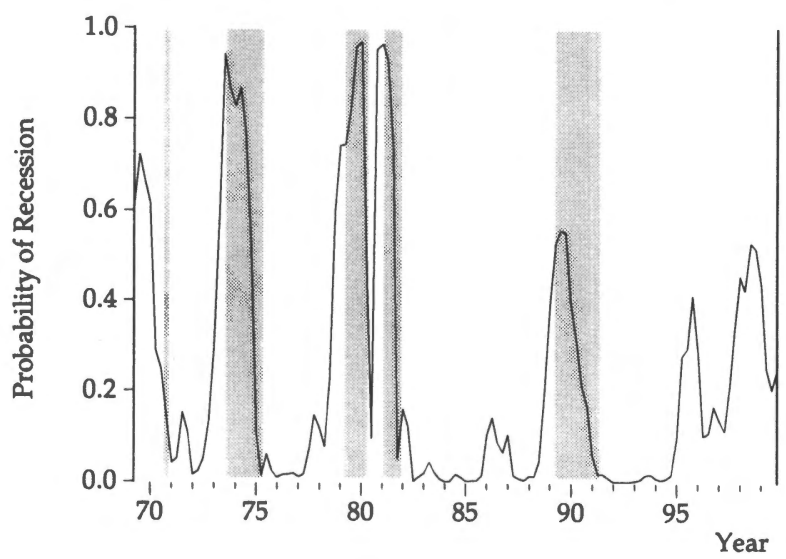

FIGURE 5

Probability of Recession: Far West Region 2 Qtr. Ahead Forecast

1969:2 - 1999:4

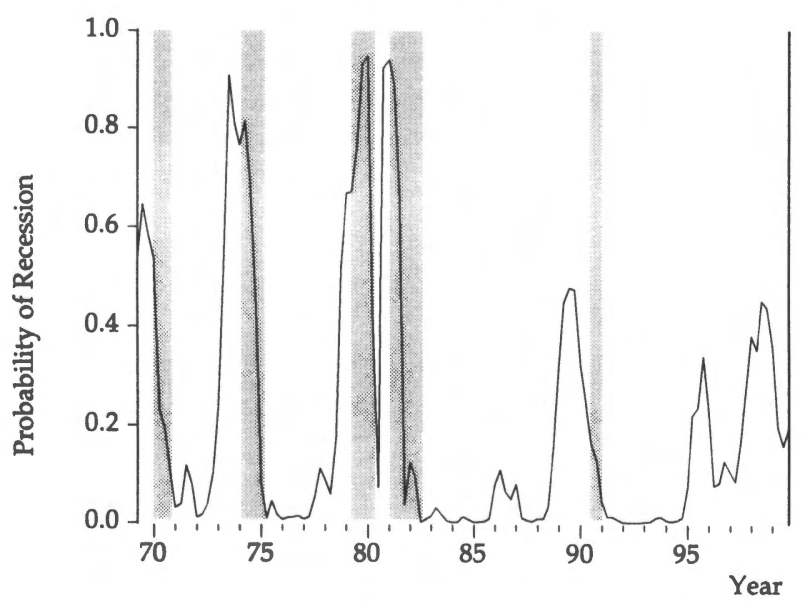


FIGURE 6

Probability of Recession: Southeast Region

2 Qtr. Ahead Forecast

1969:2 - 1999:4

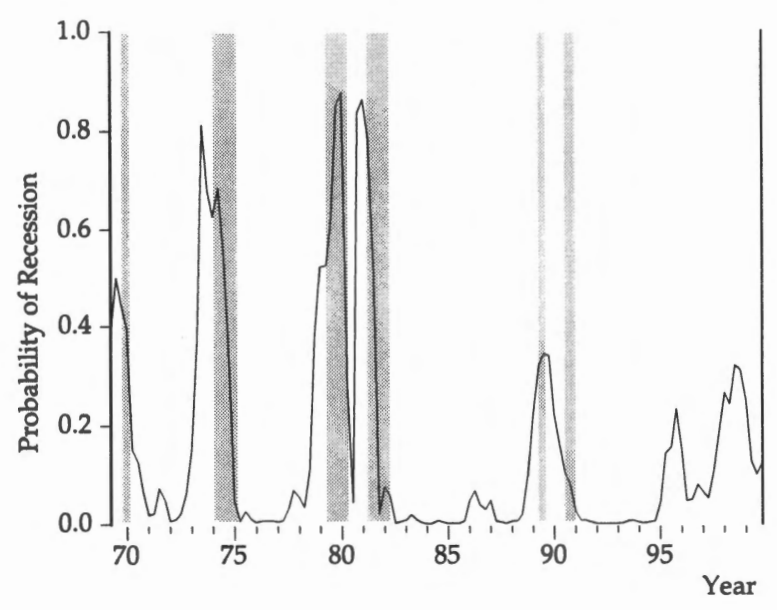

FIGURE 7

Probability of Recession: Mideast Region

2 Qtr. Ahead Forecast

1969:2 - 1999:4

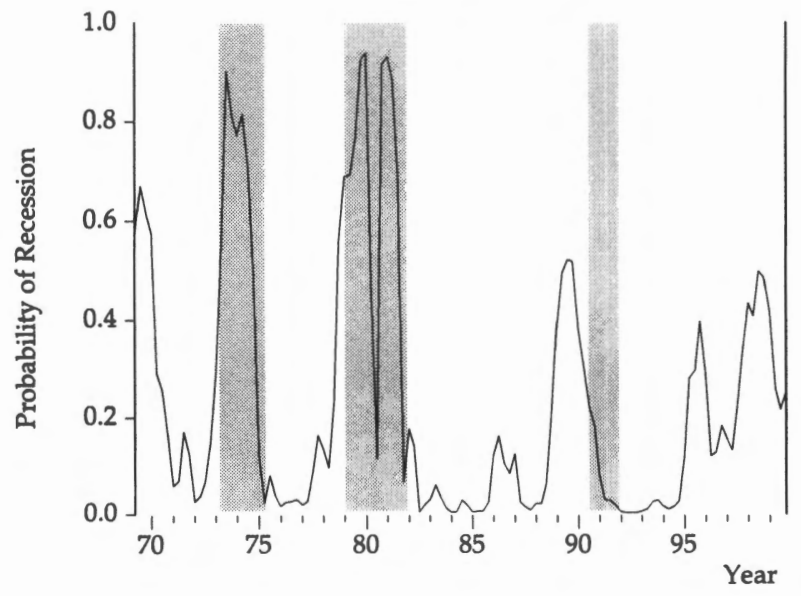


FIGURE 8

Probability of Recession: Plains Region 2 Qtr. Ahead Forecast

1969:2 - 1999:4

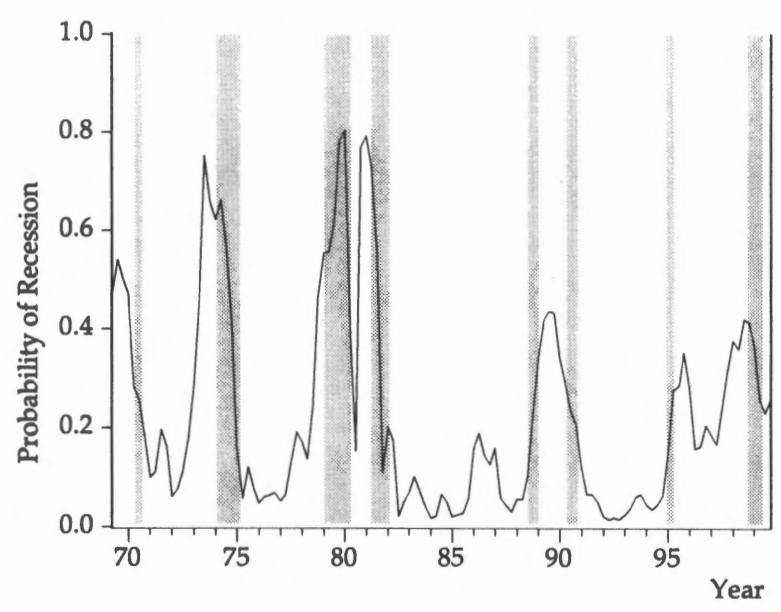

FIGURE 9

Probability of Recession: Rocky Mountain Region 2 Qtr. Ahead Forecast

1969:2 - 1999:4

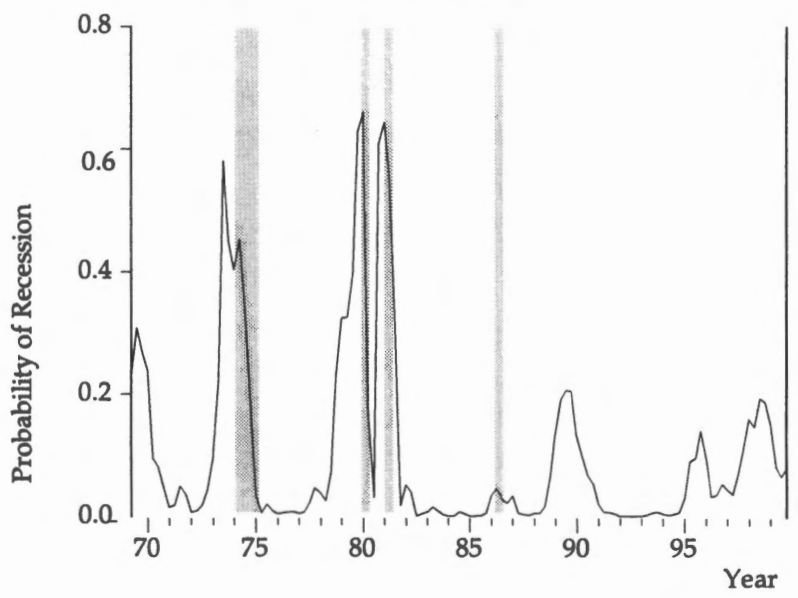




\section{FIGURE 10}

Probability of Recession: Southwest Region

2 Qtr. Ahead Forecast, 1969:2 - 1999:4

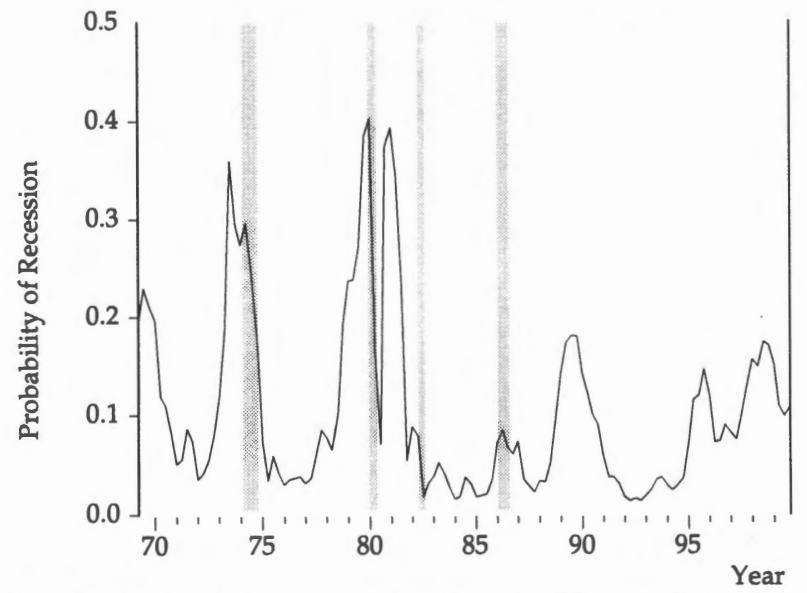

A finding that draws some attention in Figure 2 is the rising probability predictions late in 1995 and 1998, with no corresponding overt recession. Since this pattern also shows up in many of the regions' probability predictions, it warrants further discussion. In the benchmark Estrella and Mishkin (1998) study, their time period ended in 1995, so this outcome was not evident given their time frame. Closer consideration of events during these periods helps clarify what likely is driving these results. The 1994-95 episode was one of the preemptive monetary policy actions aimed at achieving a soft landing. Concern over inflationary pressures led the Federal Reserve to use contractionary monetary policy actions. In the model here, the narrowing of the yield spread (associated with the contractionary policy actions) leads to increased recession probability predictions. Over this period, there was a corresponding slowdown in the overall economy, but aggregate-level recession was avoided. (Some would say that a slowdown is an increased probability of recession; thus, the model performed well.) As is evident in the regional results below, several regions did move into recession during the 1995 policy actions. In the late 1990s, monetary policy actions were again characterized as preemptive strikes. Interest rates were increased multiple times during this period due to concerns of overheated labor markets and inflationary pressures. Again, these contractionary actions lead to increased recession probabilities predicted by the model. Late in 2001, the NBER officially declared that the aggregate economy entered a recession in March of 2001. Regional data indicate contractions or slowdowns within several regions of the economy.

Another factor to consider in interpreting the aggregate and regional results is the recent inversion of the yield curve. The government bond yield curve inversion in 1999 and 2000 has been attributed, at least in part, to the retiring of some long-term debt instruments in an era of budget surpluses. ${ }^{13}$ In the application here, the associated narrowing (or inversion) of the rate spread causes the ${ }^{13}$ In "What is the Slope of the Yield Curve Telling Us?", Neely (2000) argues that the Treasury's debt management in the late 1990s reduced the long-term bond supply and contributed to the yield curve's inversion. 
model to predict increased probability of recession at the end of the period. Neely (2000) examines this issue, and evaluates the performance of a commercial interest rate spread versus a government rate spread. He finds similar performance across both rate spreads in predicting aggregate recessions. Thus, it appears that debt retirement is not the dominant factor driving increased probability predictions.

Figures 3 and 4 show recession predictions for the Great Lakes and New England regions. Consistent with earlier indications in Table 1, the predictive performance for these regions is even stronger than for the aggregate economy. For both regions, the model sends strong signals prior to recessions, with probabilities over $95 \%$ in advance of the 1980 s recession. Signals of the 1990 recession are much stronger than were found for the overall economy (near $60 \%$ versus $40 \%$ for the overall economy). It also is evident from Figures 3 and 4 that recessions in these regions tend to be more prolonged events than for the aggregate economy. The preemptive strikes in monetary policy around 1995 and 1998 led to increased recession probability predictions from the model for all eight regions and the aggregate economy. In the 1995 episode, the aggregate economy achieved a "soft landing;" no aggregate-level recession resulted. The Great Lakes region experienced two short downturns surrounding the 1995 episode, as noted on Figure 3.

Turning to the Far West, Southeast, and Mideast regions (Figures 5, 6, and 7, respectively), performance is comparable to that for the overall economy. In all cases, predicted recession probabilities do rise in advance of regional recessions. The Mideast experienced fewer recessions over the period, but more prolonged recessions. For example, in the downturn of 1979 and the early 1980s, many regions and the aggregate economy had a brief period of recovery around 1981 . The Mideast experienced a continuous downturn over the entire period. The model sent strong signals two quarters in advance of each episode.

As the Table 1 results indicated, the Plains, Rocky Mountain, and Southwest regions showed weaker model performance than did the aggregate economy. As expected, the probability prediction results for these regions (Figures 8, 9, and 10 ) are not as strong as those for previous regions. The Rocky Mountain region did not experience frequent prolonged recessions during the sample period. As noted, the probit model does not perform as well when there are few episodes to predict, so this may be one reason for the relatively weaker performance found in Table 1 for the Rocky Mountain region. The model does send strong signals prior to the recession in the early 1980s. However, for both the Rocky Mountain region and the Southwest, the model does not predict well the 1986 recession. Factors other than monetary policy appear to have dominated economic activity in this period. Note that this was the era of increased savings and loan and bank failures (commonly called the "S\&L crisis," although it also extended to banks). Annual failures of savings and loan institutions tripled between 1986 and 1988 (from 60 to 185 failures), and spiked further in 1989 (at 327 annual failures). ${ }^{14}$ Bank failures also increased ${ }^{14}$ Source: Reports from the Federal Deposit Insurance Corporation. Available at http://www.fdic.gov/databank/. 
sharply during this period. Thus, in the Southwest and Rocky Mountains, events other than interest rate movements may dictate this regional downturn.

In the Plains, predicted probability values are not as strong as were found for the Great Lakes, for example. However, the model does signal much of the recession activity in the region. Unlike the broader economy, the preemptive strikes in monetary policy in 1995 and 1998 did cause downturns in the Plains region, as is evident from Figure 8 . This may be due to the presence of a stronger credit channel of monetary transmission in the Plains than in other regions (see Schunk 1999). Perhaps the preemptive strikes yielded real effects working through this credit channel.

The Plains region is one that is relatively dominated by small banks and small firms. In the face of a decline in bank reserves, small banks may find it more difficult to turn to alternative sources of loanable funds than larger banks. At the same time, small firms tend to be more reliant on banks than are large firms that can more readily turn to other credit markets to raise funds. Thus, in a region like the Plains with many small banks and small firms, monetary policy may work through this credit channel more so than in other regions. The Plains region could therefore have been more susceptible to the preemptive strikes during the middle and late 1990s.

Thus, the results in Table 1 and in Figures 2-10 reveal some notable differences in the predictive power across regions. It is worth assessing factors that may account for the overall patterns in the regional results. As noted, explanations for the yield spread's aggregate-level predictive power address its ability to capture monetary actions and expectations in the economy. It is difficult to make a practical case for regional differences in expectations formation..$^{15}$ Thus, attention focuses on the yield spread as an indicator of monetary actions and interest rate movements, and reasons why regions would show differing sensitivity to monetary actions.

It is expected that the magnitude of monetary policy impacts on a region should be dependent on the interest rate sensitivity of economic activity in the region. This follows from the standard interest rate channel of monetary transmission. Recent empirical studies provide consistent evidence of a link between a region's interest rate sensitivity (and sensitivity to monetary actions) and the dominance in the regional economy of sectors such as manufacturing and construction. ${ }^{16}$ Since monetary actions have strong impacts on the yield curve, this points to the interrelated issues: a region's sensitivity to monetary actions, dominance of manufacturing and construction in a regional economy, and strong predictive performance of the yield curve. Sectoral assessments of the yield spread's predictive 15 It is true that expectations can differ by regions, but there is no explanation as to how these differing regional expectations would aggregate into the expectations embodied in the national-level yield curve.

${ }^{16}$ Interest rate changes can affect sectors such as manufacturing and construction via both supply and demand channels. On the demand side, monetary actions affect borrowing costs, thus affecting the demand for automobiles, appliances, and houses. Further, while business investment typically responds more to changes in economic activity, monetary policy does alter the firm's cost of capital investment, and creates potential supply-side impacts. Finally, when interest rate changes affect overall economic activity, delayed impacts on the demand for nondurable manufactured goods often follow. 
power support this assertion. (See, for example, Estrella and Hardouvelis 1991 or Gauger and Jaradat 2001.) Strong predictive power is found in sectors such as durable goods, housing, and business investment; weak predictive power is found in sectors such as the service sector.

Results presented here for the yield spread's predictive power across regions are consistent with these patterns of manufacturing dominance. Table 2 provides a breakdown of the industry share of total regional gross state product (GSP) for the eight regions and the U.S. on average between 1977 and $1991 .{ }^{17}$ Great regional variations are evident in Table 2 . The Great Lakes region posts the highest share in these interest-sensitive sectors, at 33.0 percent. The Rocky Mountain region is the least reliant on these sectors, with just 17.9 percent of total regional output produced in manufacturing and construction.

TABLE 2

Industry Share of Regional Output Average shares of regional GSP by industry, 1977-1991

\begin{tabular}{lccccc}
\hline & $\begin{array}{c}\text { Durable } \\
\text { Mfg }\end{array}$ & $\begin{array}{c}\text { Nondurable } \\
\text { Mfg }\end{array}$ & Construction & $\begin{array}{c}\text { Durable } \\
\text { Construction }\end{array}$ & $\begin{array}{c}\text { Total Mfg + } \\
\text { Construction }\end{array}$ \\
\hline New England & 16.6 & 7.3 & 4.2 & 20.8 & 28.1 \\
Mideast & 9.9 & 8.8 & 4.0 & 13.9 & 22.7 \\
Great Lakes & 20.0 & 9.0 & 4.0 & 23.9 & 33.0 \\
Plains & 12.0 & 8.5 & 4.2 & 16.2 & 24.8 \\
Southeast & 9.1 & 11.5 & 4.8 & 13.9 & 25.4 \\
Southwest & 8.3 & 6.7 & 5.3 & 13.6 & 20.3 \\
Rocky Mountain & 7.7 & 4.8 & 5.5 & 13.2 & 17.9 \\
Far West & 10.7 & 5.3 & 4.9 & 15.6 & 20.9 \\
U.S. & 11.9 & 8.3 & 4.5 & 16.4 & 24.8 \\
\hline
\end{tabular}

In studies elsewhere that evaluate the regional responsiveness to monetary policy, findings confirm the tie between manufacturing and construction dominance and monetary impacts. As noted, the Great Lakes region consistently has been identified as the region most strongly affected by interest rate changes (see, for example, Carlino and DeFina 1998, 1999 and Schunk 1999). In Table 2, the Great Lakes region stands out as the region that is most reliant on interestsensitive production, particularly durable goods manufacturing. Also, the yield spread has been found to have the strongest recession prediction power in the Great Lakes region. Contractionary monetary policy and the corresponding flattening of the yield curve are likely to have a much stronger overall regional impact in the Great Lakes region (where automobile production accounts for nearly 5 percent of total output) than that observed in the overall economy (where automobiles account for about 1.3 percent of total output). As was evident in the recession forecast graphs, recessions in the Great Lakes region can be prolonged events, and the parsimonious yield spread model provides strong advance signals of recession in this durable goods-dominated region. New England is another region in which the yield spread model sends strong advance signals of recessions.

17The GSP data begin in 1977. The period 1977-1991 was used to calculate these shares because this period most equally represents the full sample of earnings data (1969:2-1999:4) used to predict regional recessions. 
As Table 2 shows, New England is dominated by manufacturing and construction, with these sectors accounting for 28.1 percent of total regional output. Thus, the yield curve has the best predictive power in the two regions that are most reliant on interest-sensitive production.

At the other end of the spectrum, the results indicate that the yield spread has weaker predictive power in the Plains, Rocky Mountain, and Southwest regions. Of these three regions, the Southwest and Rocky Mountain regions have the lowest shares of manufacturing and construction sector production. The yield spread has, by far, the lowest predictive power in the Southwest region. At the optimal horizon of one quarter, the pseudo $\mathrm{R}^{2}$ is just $8.5 \%$ for the Southwest. The recession probability signals for the Southwest (Figure 10) were the weakest of the entire set of regions (maximum probabilities around $40 \%$ for the Southwest, compared to almost $98 \%$ for the Great Lakes). As values in Table 2 indicate, the Southwest region generally is insulated more from the effects of monetary policy. This is largely due to its reliance on the resource extraction sector, specifically oil and gas extraction. (Resource extraction production represented 11.9 percent of the region's total output between 1977 and 1991, compared with the national average of just 2.9 percent.) Other factors dominate the extractive industries, and they are not quickly sensitive to interest rate changes and monetary actions. Correspondingly, the yield spread does not have strong power in predicting recessions in the Southwest. Similarly, the Rocky Mountain region is generally more diversified than most regions and thus less susceptible to monetary policy actions.

Indeed, only two regions appear not immediately to fit well when comparing the yield spread's power with the dominance of manufacturing and construction. The yield spread has below average predictive power in the Plains region, even though this region has an (exactly) average share of output in the interest-sensitive sectors. However, the economy of the Plains region is much more dependent on agriculture than are other regions (with 6.5 percent of regional output in agriculture compared with 2.2 percent for the nation as a whole). Thus, the Plains region is similar to the Southwest in that the regions' manufacturing and construction sectors' response to interest rate changes is largely offset by a relatively large sector that is not quickly sensitive to monetary policy actionsagriculture in the Plains, mining in the Southwest. The yield spread had solid predictive power for recessions in the Far West, even though the region has a below average share of output in the manufacturing plus construction sectors. However, the Far West region has above average concentrations of both construction and of lumber and woods products manufacturing-key inputs to the construction sector. ${ }^{18}$ This tie to construction activity likely boosts the yield spread's predictive performance for this region.

Overall, the patterns for the yield spread's regional predictive power found in this study are consistent with previous evidence on regional monetary impacts. In regions where manufacturing and construction are important components

${ }^{18}$ Looking at construction and durable goods manufacturing, the Far West is indeed near the national average concentration. 
of regional activity, national monetary policy can have important regional consequences. Results here show that the yield spread model is a simple framework that can provide strong predictive power for recessions in these regional economies.

\section{CONCLUSIONS}

Predicting recessions is among the toughest tasks faced by forecasters, though it is of constant interest among macroeconomic economists, observers, and financial market participants. While many factors may contribute to a recession, recent empirical work has identified the yield spread as a reliable and parsimonious factor useful for prediction recessions. Estrella and Mishkin (1998), for example, find that the yield spread outperforms other commonly considered variables in predicting U.S. recessions within a relatively simple probit model. Of particular interest from this type of model is the fact that a recession probability can be calculated in a straightforward way. This information is of course valuable to policy makers and observers at the national level. However, because the national economy is comprised of geographically and economically diverse regions, the probability of a national recession does not necessarily reflect the probability of a regional recession. Because regional recessions vary in terms of their timing and magnitude, it is important to understand how well the yield curve performs as a predictor of regional recessions.

This study has clearly illustrated dramatic differences between regions in terms of the yield spread's ability to predict recessions. The results have indicated that the U.S. yield spread has average recession predictive power in some regions, above average predictive power in a group of regions, and below average power in a third group of regions. Understanding why this should be the case relies on understanding what information contained in the yield spread should be useful in predicting recession in general. Though the yield curve contains information about expectations, it is not straightforward to rely on this content to explain regional differences. Rather, the explanation appears to lie in the yield spread as an indicator of monetary policy.

Those regions in which the yield spread has relatively high predictive power-the Great Lakes and New England regions-have also consistently been identified as regions that are relatively highly responsive to changes in monetary policy. Working through a traditional interest rate channel, monetary policy has a strong impact on these regions that are heavily dominated by interest-sensitive production in the manufacturing and construction sectors. Viewing changes in the yield spread as capturing changes in monetary policy, it should be expected that areas that are highly affected by policy changes would be the same areas in which the yield spread should be best suited to predicting regional recessions. Similarly, both the Rocky Mountain and Southwest regions are substantially less dominated by manufacturing and construction and are regions in which the yield spread does not serve as a powerful predictor of recessions.

The results of this study are important for two key reasons. First, this assessment contributes to the evidence on the yield spread's predictive power and 
adds to the explanation of why the yield curve should be so useful. In particular, the pattern of regional predictions, when considered along with the pattern of regional economic structure, highlights the importance of the monetary policy content of the yield curve. Second, the results indicate the extent to which regional economic observers should place confidence in the yield curve as a predictor of recessions in their own region. That is, a regional forecaster in the Great Lakes should look more closely at changes in the slope of the yield curve than should a forecaster in the Southwest region.

\section{REFERENCES}

Carlino, G., and R. DeFina. "The Differential Regional Effects of Monetary Policy." The Review of Economics and Statistics 80 (1998), 572-87.

. "The Differential Regional Effects of Monetary Policy: Evidence from the U.S. States." Journal of Regional Science 39 (2) (1999), 339-58.

Cohen, B. The Geography of Money. Ithaca, N.Y.: Cornell University Press, 1998.

Estrella, A. "A New Measure of Fit for Equations with Dichotomous Dependent Variables." Journal of Business and Economic Statistics 16 (1998), 198-205.

Estrella, A., and G. Hardouvelis. "The Term Structure as a Predictor of Real Economic Activity." Journal of Finance 46 (2) (1991), 444-76.

Estrella, A., and F. Mishkin. "Predicting U.S. Recessions: Financial Variables as Leading Indicators." The Review of Economics and Statistics 80 (1) (1998), 45-61.

. "The Yield Curve as a Predictor of U.S. Recessions." Federal Reserve Bank of New York Current Issues in Economics and Finance 2 (7) (1996), 1-7.

Estrella, A., A. Rodrigues, and S. Schich. "How Stable is the Predictive Power of the Yield Curve? Evidence from Germany and the United States." Federal Reserve Bank of New York Working Paper, September 2000.

Garrison, C., and H. Chang. "The Effect of Monetary and Fiscal Policies on Regional Business Cycles." International Regional Science Review 4 (2) (1979), 167-80.

Gauger, J., and H. Jaradat. "Consumer Sentiment and Recession Predictions: New Information or Added Noise?" Department of Economics, University of Tennessee, November 2001.

Goldberger, A.S. Econometric Theory. New York: Wiley, 1964.

Maddala, G.S. Limited Dependent and Qualitative Variables in Econometrics. New York: Cambridge University Press, 1983.

Neely, C. "What is the Slope of the Yield Curve Telling Us?" Federal Reserve Bank of St. Louis Monetary Trends (August 2000), 1.

Schunk, D. "Regional Dynamics: Heterogeneous Regional Responses to Money and Interest Rates and the Role of Alternative Monetary Aggregates." Ph.D. diss., part 3, The University of Tennessee, 1999.

Toal, W. "Regional Impacts of Monetary and Fiscal Policies in the Postwar Period: Some Initial Tests." Federal Reserve Bank of Atlanta Working Paper, 1977.

Warf, B., and J. Cox. "U.S. Bank Failures and Regional Economic Structure." Professional Geographer 47 (1995), 3-16. 